\title{
EXPLICAÇÃO DO CONTEÚDO: ELEMENTO ESTRUTURANTE DA APRENDIZAGEM EFICAZ
}

\author{
MARILDA DA SILVA \\ Faculdade de Ciências e Letras/Unesp - Araraquara \\ marilda_d@hotmail.com
}

\begin{abstract}
RESUMO
Neste artigo busca-se mostrar a construção de uma categoria explicativa do trabalho docente denominada "explicação do conteúdo", a partir de representações de alunos da Habilitação Magistério sobre as práticas pedagógicas de seus professores, cuja formulação assumiu a função de "elemento estruturante básico do trabalho docente eficaz". Trata-se de pesquisa de abordagem qualitativa em que os instrumentos utilizados para coleta de dados foram observação em sala de aula e entrevista semi-estruturada.

FORMAÇÃO DEPROFESSORES - TRABALHO DOCENTE-ENSINO-APRENDIZAGEMSALA DE AULA - DIDÁTICA
\end{abstract}

\section{ABSTRACT}

CONTENT EXPLICATION: THE BASIC STRUCTURING ELEMENT OF EFFECTIVE $\angle E A R N I N G$. This article aims to demonstrate the construction of an explanatory category of teaching called "content explication". It is based on Teacher's school students representations about the pedagogical practices of their teachers, whose formulation assumed the function of "basic structuring element for effective teaching work". The approach is qualitative and the procedures are classroom observation and semi-structured interviews.

Este artigo faz parte da tese intitulada: As experiências vividas em formação e a constituição do habitus professoral: implicações para o estudo da didática, defendida, em 1999, na Faculdade de Educação da Universidade de São Paulo sob a orientação de Denice Barbara Catani. 
Na última década muitos foram os estudos sobre a formação de professores que buscavam explicar a escola pública brasileira e contribuir para a melhoria da sua qualidade. A pesquisa que ora se apresenta também busca esse intento, contudo, o faz a partir das representações que alunos manifestam sobre o procedimento pedagógico considerado por eles eficaz para a sua aprendizagem. Mostra-se assim a construção de uma categoria que se denominou neste estudo "explicação do conteúdo", que também foi importante, no caso, para se compreenderem as práticas pedagógicas realizadas nas escolas. A formulação dessa categoria permitiu, simultaneamente, circunscrever o procedimento didático do trabalho docente esperado e desejado por alunos, levando a se atribuir à "explicação do conteúdo" a função de elemento estruturante básico do processo ensino-aprendizagem na sala de aula.

Percurso do trabalho iniciou-se em 1987, com uma pesquisa realizada com 550 alunos das quatro séries da Habilitação Magistério pertencentes a grandes e antigos institutos de educação localizados em três cidades do Estado de São Paulo: Araraquara, São Carlos e Ribeirão Preto. O objetivo desse estudo foi verificar que disciplina o grupo de alunos considerava mais adequada para se ensinar a ensinar, no contexto da formação de professores para as primeiras séries do ensino fundamental, e quais eram as representações que tinham da forma pela qual a disciplina eleita era a eles ministrada.

Dos resultados obtidos interessa nesse caso a constatação de uma imensa insatisfação explicitada pelo grupo com o modo pelo qual as aulas eram ministradas nos três cursos aos quais pertenciam. Com base nesse resultado realizou-se outra pesquisa, utilizando-se de procedimento empírico numa das escolas na qual parte dos 550 alunos pesquisados anteriormente havia estudado. Como o primeiro resultado havia sido fruto de pesquisa qualitativa cujo instrumento foi um questionário com perguntas abertas e fechadas, não tendo havido observação em sala de aula e entrevista, optou-se posteriormente por esses últimos procedimentos. Desse modo seria possível observar como os professores de parte do grupo de 550 alunos ministravam suas aulas, uma vez que o corpo docente no início dos anos 90 ainda era o mesmo de 1987 na instituição. Ademais, permitiria verificar o que outro grupo de alunos dizia sobre tais modos. Por se tratar de um curso que prepara professores, decidiu-se observar aulas das disciplinas cujo objetivo específico é ensinar o aluno a ensinar: Conteúdo e Metodologia do Ensino de Língua Portuguesa, Ciências, Matemática e Didática. Partiu-se do pressuposto de que esse era um ambiente fértil para se apreender a apreciação das alunas sobre a constituição dos modos do fazer 
didático. Essa pesquisa foi realizada no início dos anos 90 e a análise e interpretação concluídas em 1998, tendo se beneficiado de valiosa contribuição do trabalho realizado por Alda Junqueira Marin e Maria lolanda Monteiro.

Os dados apresentados a seguir foram coletados por meio de observação em sala de aula e de entrevistas.

\section{PRIMEIROS PONTOS FIXOS DA CATEGORIA “EXPLICAÇÃO DO CONTEÚDO"}

A "explicação do conteúdo" como categoria explicativa do trabalho docente, desejado por estudantes da Habilitação Magistério (Araraquara-SP), começou a ser construída em 1991, a partir da observação de uma aula ministrada para efeito de estágio supervisionado de Prática de Ensino - por duas alunas da Graduação em Pedagogia da Faculdade de Ciências e Letras - Unesp - campus de Araraquara. Como atividade didática as estagiárias apresentaram à três turmas do período matutino ( $3^{\mathrm{a}}$ e $4^{\mathrm{a}}$ séries - em torno de 60 alunas) um vídeo sobre as idéias de alfabetização de Emília Ferreiro. Logo no início dessa apresentação, a professora responsável pelas turmas, com tom um tanto ríspido, pediu que as alunas anotassem "alguma coisa", pois deveriam fazer um relatório sobre o conteúdo da atividade que seria desenvolvida pelas estagiárias. $\bigcirc$ descontentamento das alunas foi generalizado.

Durante a primeira parte da regência, que consistiu na apresentação de um vídeo com interferências pontuais feitas por uma das estagiárias, as alunas ficaram quietas, mas não atentas. $\bigcirc$ segundo momento da regência foi de responsabilidade de outra estagiária que esclareceu questões conceituais da proposta e deu indicações sobre como os conceitos poderiam contribuir, de acordo com a autora em questão, para o exercício da alfabetização no contexto brasileiro. Com desenvoltura, a expoente estabelecia relações de afinidade entre a psicologia, a sociologia e a didática, exemplificando sobretudo com problemas corriqueiros do processo de alfabetização que ocorrem em escolas públicas do país. Nessa etapa as turmas foram aos poucos mudando de comportamento, isto é, as alunas manifestaram interesse pela explicação. Aquelas que estavam no fundo da sala sentadas em cima das carteiras, e que nada anotavam, voltaram-se para a estagiária, que continuou sua explicação. Quando ela terminou, perguntou se havia alguma questão a ser feita ou dúvida a ser dirimida. Uma aluna fez uma pergunta que foi complementada por outra e a discussão fluiu. Mas, quando a professora interveio para esclarecer que 
"havia dado apenas os métodos tradicionais de alfabetização", um novo burburinho fez-se ouvir. As alunas ausentaram-se das discussões do tema proposto e apenas a professora e a estagiária continuaram a falar sobre o assunto.

Era muito cedo para se ter uma idéia do que se passava entre as alunas e a professora. Contudo, não parecia ser algo desvinculado do modo pelo qual a professora ministrava as aulas e do que a estagiária havia ensinado em ocasião obrigatória, porém, circunstancial. O que fez a estagiária de tão extraordinário para ter convencido as alunas a prestarem atenção em sua aula? A regente apenas explicou o que havia proposto e nem o uso de um vídeo, portador de indiscutíveis qualidades teóricas, pedagógicas e técnicas, superou a explicação oferecida.

Embora se reconhecesse que os acontecimentos desse primeiro dia de observação fossem, por várias razões, insuficientes para se levantar, a partir deles, qualquer hipótese, resolveu-se seguir na direção por eles apontada: a "explicação do conteúdo" poderia ser a chave que abriria a compreensão das práticas pedagógicas exercidas pelos professores cujas aulas seriam observadas. A decisão, ainda temerária, fundamentava-se no estudo realizado em 1987, já mencionado. Os dados coletados no momento não mostravam suficientemente que a "explicação do conteúdo" constituía-se em categoria passível de ser utilizada como elemento-chave à compreensão da estrutura dos modos didáticos utilizados para ensinar nas escolas. Mostravam, contudo, que os alunos escolhiam as disciplinas pelo modo como eram ministradas pelo professor e não pela natureza de cada uma delas. Ora, se a "explicação do conteúdo" foi responsável pela atenção das alunas cujos professores eram os mesmos do grupo da pesquisa anterior, então, deveria haver nesse procedimento alguma raiz da questão que se buscava esclarecer: como eram constituídos os modos didáticos apreciados, ou não, pelas alunas da Habilitação que tornavam o ensino eficaz.

Observaram-se 25 aulas, sendo: I I no período diurno e 14 no período noturno. Em média, cada sala era composta por aproximadamente 30 alunas. A partir da observação de gestos e falas das alunas que, de um modo ou de outro, eram respostas ao trabalho que o professor realizava naquele momento, foi possível manter a hipótese que já se havia levantado na primeira observação: a "explicação do conteúdo" consistia no elemento estruturante básico do trabalho docente, constituindo, ao mesmo tempo, uma categoria explicativa desse ofício. 


\section{A “EXPLICAÇÃO DO CONTEÚDO” NO DIA-A-DIA DO ENSINO ESCOLARIZADO}

A idéia de que a "explicação do conteúdo" constitui uma categoria explicativa dos modos do fazer docente e do sucesso da aprendizagem foi construída a partir dos seguintes elementos: tempo didático de ensino e resposta corporal. $\bigcirc$ tempo didático de ensino diz respeito ao intervalo de tempo em que o professor explica: um determinado conteúdo diretamente ligado à disciplina, informações diretamente ligadas à formação docente, mas que não estão diretamente relacionadas ao conteúdo da disciplina e, ainda, questões do âmbito da educação escolarizada de modo geral. $\bigcirc$ tempo didático de ensino, na grande maioria das vezes, não ultrapassa os 20 minutos. Sobre esse tempo da explicação pode-se reportar aos dados de Maria Helena Galvão Frem Dias da Silva, coletados a partir de observações feitas em classes de $5^{\mathrm{a}}$ séries:

Já afirmei que não presenciei as clássicas aulas expositivas. E as explicações sobre o assunto, se são freqüentes, muitas vezes se restringem a 10 ou 15 minutos. As explicações ocorrem a título de introdução para aos "exercícios", ou muitas vezes à leitura do "ponto" no livro, entrecortada por uma ou outra questão formulada por algum aluno mais participante, conforme relatado no registro das aulas. Algumas vezes o próprio professor instiga as crianças com alguma questão sobre o conteúdo exposto, ou formula algum exemplo adicional ao do livro (muito comum em matemática), mas raramente esse processo dura mais que dez minutos. (1992, p. 93-94)

Note-se que o tempo de explicação do conteúdo é também muito curto no ensino fundamental. E isso, ao que parece, não diz respeito ao tempo de duração das aulas de maneira geral e sim aos modos de se ensinar na sala de aula nas escolas brasileiras.

Já a resposta corporal diz respeito à movimentação do corpo das alunas durante as situações de ensino às quais eram submetidas. Observou-se que nas aulas em que a explicação ultrapassava a leitura do texto, a postura corporal exibida pelas alunas era uma, e nas aulas nas quais o procedimento didático utilizado para ensinar era meramente a leitura do conteúdo, a postura corporal mudava. Exceto quando se tratava de aula após o intervalo, isso vale para o período diurno e para o período noturno. Nas aulas produzidas por apenas leitura os corpos das alunas necessitavam de algum apoio. Quando as cabeças não eram apoiadas pelas respectivas mãos, a parede e as carteiras serviam de apoio para que se pudesse nelas 
descansar o corpo, seja lá de que modo fosse. Todavia, sempre que o professor indicava que iniciaria uma explicação seus corpos eram sacudidos por algum interesse. Visivelmente, esse interesse desaparecia quando a explicação era trocada, conscientemente ou não, pela repetição literal do que estava escrito no texto, por meio da leitura em voz alta feita por uma aluna ou pelo profissional que se ocupava da classe naquele momento.

Pierre Bourdieu (1983, p. 83) discorre sobre esses movimentos corporais harmônicos, individuais e coletivos. Conforme o autor, a unicidade na postura exibida pelas alunas caracteriza a hexis corporal, um modo de se comportar coletivamente no âmbito de determinada prática social. E esses gestos - movimentos corporais/expressões específicos em uma determinada prática -, devem ser compreendidos, neste caso, como manifestações mentais que objetivamente são mostradas pelo corpo.

Embora se explique pontualmente tempo didático de ensino e resposta corporaleles só podem ser compreendidos em estado de amálgama, já que nenhum deles ocupa lugar privilegiado na construção da "explicação do conteúdo" como categoria explicativa do trabalho docente e como elemento estruturante básico da aprendizagem.

A pergunta que se colocou até essa altura da pesquisa foi: será que aquele grupo tinha consciência das razões que o levavam a, inconsciente e harmonicamente, responder ao trabalho do professor daquele modo? Essa preocupação se justificava na medida em que se estava trabalhando com a idéia de representação de Bourdieu.

Os dados que corroboram os antes apresentados, pela necessidade metodológica apontada no parágrafo anterior, foram coletados mediante entrevista. Catorze alunas das $4^{\text {as }}$ séries do ano letivo de 1991, com as quais se havia feito as observações participaram dessa etapa da pesquisa'. Optou-se, portanto, por entrevistar apenas alunas do último ano da Habilitação, porque elas tinham mais experiência no curso do que as alunas das $3^{\text {as }}$ séries. As alunas que decidiram conceder a entrevista optaram pela entrevista coletiva e constituíram, no início de 1992, quatro grupos: três de quatro alunas e um de duas alunas. Dois dos grupos eram compostos por quatro alunas das $4^{\text {as }}$ séries do diurno e do noturno $\left(4^{\mathrm{a}} \mathrm{B}\right.$ e $\left.4^{\mathrm{a}} \mathrm{C}\right)$ e o outro

I. Em 199| a Habilitação Magistério oferecida naquela escola tinha 835 alunos, divididos em 23 classes, distribuídas nos períodos: matutino, vespertino e noturno. Desses 835 alunos, 118 cursavam a $3^{\mathrm{a}}$ série e 106 a $4^{\mathrm{a}}$ série. 
por quatro alunas da $4^{\mathrm{a}}$ série do diurno ( $\left.4^{\mathrm{a}} \mathrm{A}\right)$; e mais o grupo composto por duas alunas da $4^{\mathrm{a}}$ série $\mathrm{C}$. $\bigcirc$ procedimento utilizado foi o da entrevista semi-estruturada e a análise foi temática e não de discurso. Sua organização deu-se a partir da temática: quais as representações que as alunas da Habilitação construíam a respeito dos modos didáticos utilizados por seus professores para ensinar os componentes curriculares: Conteúdo e Metodologia do Ensino de Matemática, de Ciências e de Língua Portuguesa e Didática, já que a observação havia sido feita nas aulas dessas disciplinas. Os depoimentos foram do tipo:

Eu acho o seguinte: a maneira como eles dão aula lá, eu não gosto. Eles só lêem, não explicam nada.

[...]

Ela pedia para a gente dividir o livro em capítulos e expor lá na frente e explicar. Se a gente está lá para aprender, não é a gente que vai explicar. Ela pedia para pesquisar, tudo bem... É ótimo, mas eu acho que ela tinha que transmitir muita coisa antes, e ela transmitiu muito pouco. Ela foi muito mais exigente no caso... entre nós aprendermos. E isso é uma coisa que terminando o curso, a gente vai fazer mesmo sozinha. Agora, durante o curso, deveria ser aproveitado pra dar muita coisa que sozinha a gente não consegue, algumas explicações que, por exemplo, se lê num livro... Fica sempre alguma coisinha em dúvida que nós não conseguimos responder... Teria que ser a professora de Didática a fazer isso e ela tende a deixar a gente fazer sozinha.

$[\ldots]$

Ela sempre deu muita coisa pra fazer. Todo mundo sempre trabalhava o dia inteiro e ainda chegar à noite e levar trabalho pra casa? Deveria ser discutido lá, lido lá, explicado lá. Como, por exemplo, na matéria de Metodologia de Língua Portuguesa eu pedi para professora explicar sobre a Emilia Ferreira (sic)... Que a gente não está conseguindo entender, eu estou tentando ler, está muito difícil... Eu pedi pra ela explicare ela não explicou nada. Lembro que um dia ela só passou uns vídeos, mas eu pedi: "explica para a gente direitinho, qual é o projeto dela". Ela não explicou, rodeou, rodeou passou para outra matéria e não explicou. E foram umas alunas daqui que foram apresentar o trabalho, explicar, falar sobre o assunto. Mas, mesmo assim eu acho que esse projeto é muito complexo para tão pouco; ela deveria ter falado e não falou... Ter comentado...

É curioso, pois, que no último relato a aluna tenha-se reportado à primeira aula ${ }^{2}$ ministrada pelas estagiárias da graduação em pedagogia. E foi exatamente a

2. Para maiores esclarecimentos essa aula aconteceu no dia 29 de outubro de $199 \mid$ e as entrevistas foram realizadas de fevereiro a abril de 1992. 
partir dessa regência que se percebeu a existência de um problema entre as alunas daquela Habilitação e a professora, e que se levantou a hipótese de que tal problema dizia respeito aos modos pelos quais eram ministradas as aulas na instituição para aquele grupo. Já naquele momento evidenciou-se a "explicação" como o elemento estruturante básico do trabalho docente. É muito fecundo o comentário que a aluna faz sobre essa aula ministrada pelas estagiárias, anteriormente registrada:

E foram umas alunas daqui apresentar o trabalho, explicar, falar sobre ela. Mas, mesmo assim eu acho que esse projeto é muito complexo para tão pouco, ela deveria ter falado e não falou... Ter comentado...

Note-se que a aluna não disse que não aprendeu com a explicação dada pelas estagiárias. Disse, sim, que o "tempo" de explicação foi curto para um projeto que ela considera complexo. Nesse sentido, a boa aula é também, de acordo com esse grupo, aquela cuja explicação está em primeiro plano. Como podemos observar nas seguintes considerações:

Uma aula boa: a professora chega, cumprimenta os alunos, pega o livro, explica, lê, tira dúvida, chama a atenção de alguém, pergunta se entendeu ou não entendeu, dá um exemplo.

$[\cdots]$

Como acontecia em Matemática, às vezes a gente pedia pra ela explicar e retomar alguma coisa que a gente não entendia, ela nos dizia que no quarto magistério a gente já tinha que estar sabendo tudo isso. Mas, se os professores anteriores não haviam passado? Como é que a gente ia estar sabendo?

[...]

Alguns eram ótimos pelo menos a de Psicologia, eu adorava a professora. Tudo o que eu tinha de problemas eu falava com ela. Ela parava pra escutar a gente, explicava quantas vezes precisasse.

$[\ldots]$

Não é aquele tipo de professor que só fica lendo... A maioria só lê. Ela não. Explicava mesmo... Sem ler.

$[\ldots]$

...não explicava tudo o que a gente queria saber. Ela sempre deixava a desejar, eu acho. Porque eu sempre perguntava mais e mais. E esse mais e mais que eu perguntava além da matéria ela não explicava. Porque pra mim não bastava só aquilo que estava no livro e que ela estava explicando. Muitas vezes eu falava: explica melhor sobre isso. 
Outro dado que confirma os resultados obtidos com a análise da observação em sala de aula é que a leitura de determinado conteúdo sem a "explicação" não é um procedimento adequado na produção da aula, tampouco eficaz para a aprendizagem. Essa manifestação dizia respeito ao fato de o professor ler o livro na sala de aula e também quando a aluna estava tentando sozinha compreender algo apenas pela leitura, sem a "explicação". Como se pode apreender da seguinte observação: "tinha coisa que a gente lia, lia e não entendia, dava vontade de rasgar tudo". E outra aluna respondeu: "a gente precisava da base ali, na hora... Elas não deram". E ainda:

A professora lia e a gente acompanhava, ou cada aluno lia um trecho. Mas, não tinha explicação. Porque você tem que ler um texto e trocar em miúdos para o aluno. E você assistiu à aula do... Ficava lendo aqueles livrinhos lá... Só lemos os livros. Eu achava difícil a leitura deles. Não era coisa fácil de se entender. Ficava sem entender mesmo, ele fazia perguntas nas provas e a gente não sabia o que responder. E ele não explicava.

Nesse sentido, embora não se possa dizer muito sobre o significado que esse grupo atribuía à "explicação do conteúdo", as alunas tinham idéia de que a explicação é um procedimento que exige do professor uma formação consistente e que deveria se manifestar quando ele "explicasse" o conteúdo do texto que estava sendo estudado, com informações que não estivessem registradas naquele material escrito. Nessa medida, o grupo mostrou ser a "explicação" uma atividade que exige estabelecimento de relações com outros saberes sistematizados, exigindo, sobretudo, domínio do conteúdo, em sentido amplo, com o qual se está trabalhando, tendo em conta a transposição didática defendida por Philippe Perrenoud (1993). Tais dados, simultaneamente, mostraram ainda que a "explicação do conteúdo", para ser eficaz, precisa conter exemplos da vida prática. Ou seja, é preciso mostrar ao aluno as possíveis alternativas que um determinado conteúdo pode oferecer para a compreensão das realidades com as quais ele se depara, independentemente da sua natureza. A definição de "explicação do conteúdo" a partir dos dados coletados diz: o exercício que tem por tarefa detalhar, por meio de diversas relações, um determinado conteúdo, tendo em vista oferecer recursos para se compreender ações práticas ou para enriquecê-las e, ainda, para realizar novas práticas.

Entre os pesquisadores que se dedicam ao assunto, Marin e Monteiro ( 1998) contribuem para melhor entender a função da "explicação" no âmbito das práticas pedagógicas. Mostram que alunos de l ${ }^{\mathrm{a}}$ a $4^{\mathrm{a}}$ série do ensino fundamental - de uma escola pública carente, situada na mesma cidade em que está sediada a escola que 
freqüentaram os sujeitos deste estudo -, quando solicitados a expressarem qual atitude tomam na sala de aula para compreender o que a professora está ensinando, dizem que pedem a ela para "explicar" novamente. Como se pode constatar nos depoimentos extraídos do referido trabalho: "A gente pede para explicar de novo, ela não explica, ela fala que já explicou um monte de vezes ( $3^{a}$ série, grifo nosso). E ainda: "... ela fala para eu sentar e não explica para mim".

Evidenciam-se, pois, nesses depoimentos de alunos de $3^{\mathrm{a}}$ série e de ciclo básico coletados em 1997, as mesmas questões encontradas nos depoimentos das alunas da 4ª série da Habilitação Magistério, coletados em 1992. O aluno solicita que a professora "explique" o conteúdo e a professora, nos dois casos, não atende às solicitações feitas. Assim, nem a distância temporal entre uma e outra pesquisa e nem a diferença entre os níveis de ensino interferem nos resultados obtidos nas duas investigações.

\section{CONCLUSÃO}

Evidenciou-se, mediante os dados apresentados, que é pela "explicação do conteúdo" que se aprende algo. É à ação didática de explicar ${ }^{3}$ que o aluno recorre para dizer por que aprendeu e por que não aprendeu o conteúdo que o professor pretendia ensinar. Essa força da "explicação do conteúdo" na aprendizagem eficaz pode ser, talvez, considerada por alguns de pouca utilidade, já que a "explicação" desde há muito é inerente ao ensino de algo, até quando se reporta às diferentes formas de entender a explicação no âmbito das diversas propostas pedagógicas. Todavia, não se pode negar que essa categoria explicativa, do modo como foi expressa, indica que o trabalho docente tem uma "estrutura clássica", denominada nesta investigação elemento estruturante básico do trabalho docente, que vem sendo substituída por outra, qual seja, "a leitura do conteúdo sem a explicação". E mais, esse novo elemento estruturante básico do trabalho docente está sendo estabelecido pelo professor, mas não é aceito pelo aluno.

O problema que os alunos apresentam diz respeito a um procedimento didático, constituído por um grupo específico de ações pedagógicas, da ordem prática do exercício do trabalho docente. Trata-se da "explicação do conteúdo" que se manifesta como um procedimento didático imprescindível para se pensar os modos

3. Sobre essa questão da explicação possibilitar a aprendizagem vale a pena consultar Scheffler (1974, cap. I, 4, 5). 
de ensinar na sala de aula, tendo em vista o registro histórico das práticas pedagógicas exercidas na escola brasileira.

\section{REFERÊNCIAS BIBLIOGRÁFICAS}

BOURDIEU, P. A Força da representação. In: - A Economia das trocas lingüísticas: 0 que falar quer dizer. São Paulo: Editora da Universidade de São Paulo, 1996. p. I07-I I6. . Gestos de classe e estilos de vida: sociologia. ORTIZ, R. (org.). São Paulo: Ática, 1983. p. 82-121.

MARIN, A. J.; MONTEIRO, M. I. Reações de crianças e professores diante da dificuldade de entendimento em salas de aula: a visão dos alunos. Nuances: Revista do Curso de Pedagogia, Presidente Prudente, v. 4, n. 4, p. 100-106, 1998.

PERRENOUD, P. Práticas pedagógicas, profissão docente e formação: perspectivas sociológicas. Lisboa: D. Quixote, Instituto de Inovação Educacional, 1993.

SCHEFFLER, I. A. A Linguagem da educação. São Paulo: Saraiva, USP, 1974.

SILVA, M. H. G. F. D. O Professor como sujeito do fazer docente: a prática pedagógica nas $5^{a}$ séries. São Paulo, 1992. Tese (dout.) Faculdade de Educação, Universidade de São Paulo.

SILVA, M. O Alunado de uma escola particular noturna de formação de professores. Revista Didática, São Paulo, v. 29, p. 45-53, 1994.

As Experiências vividas em formação e a constituição do habitus professoral: implicações para o estudo da didática. São Paulo, 1999. Tese (dout.) Faculdade de Educação, Universidade de São Paulo.

SILVA, M.; MARIN, A. J. Didática e formação de professores a nível de $2^{\circ}$ grau: o cotidiano na visão dos alunos. Revista Didática, São Paulo, v. 25, p. 63-78, 1989. 